\title{
Editorial
}

\section{La asistencia al parto: del hogar al hospital}

\section{Assistance for childbirth: home to hospital}

\section{Assistência de parto: de casa para o hospital}

\author{
$M^{a}$ Ángeles Castaño Molina \\ Matrona. Profesora Asociada de la Universidad de Murcia
}

Cómo citar esta editorial en edición digital: Castaño Molina, Ma A. (2014) La asistencia al parto: del hogar al hospital. Cultura de los Cuidados (Edición digital) 18, 39. Disponible en: http://dx.doi.org/10.7184/cuid.2014.39.01>

Correspondencia: Facultad de Enfermería. Campus Universitario de Espinardo. CP 30100 Murcia.

Correo electrónico: angeles.castano@um.es

Recibido: 1/03/2013; Aceptado: 15/05/2014

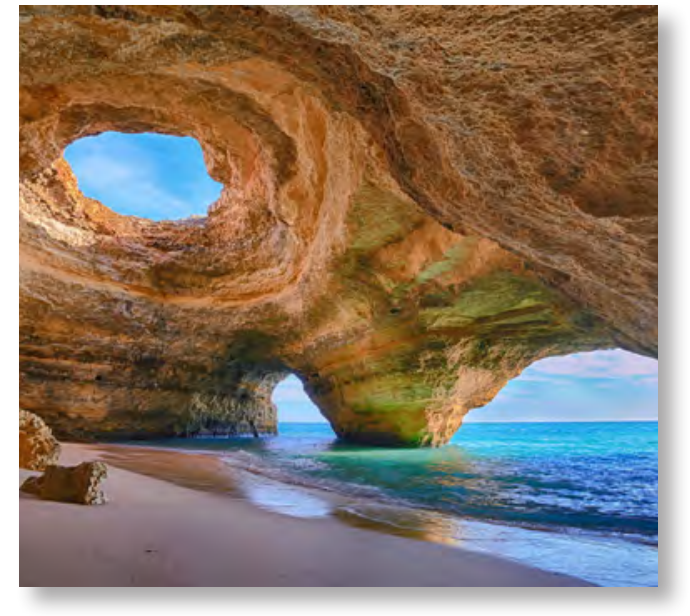

Durante el siglo XX se produjeron numerosos cambios en el manejo del parto existiendo un aumento gradual de la asistencia hospitalaria. En la década de los noventa, casi el $100 \%$ de las mujeres europeas acudían a los hospitales para dar a luz; sin embargo, en Holanda el 35\% de los partos eran domiciliarios y en el Reino Unido se aconsejó en 1992 que para las madres de bajo riesgo debía haber un retorno a la asistencia del parto domiciliario.

Los nuevos conocimientos en farmacología se aplicaron al momento del parto; así por ejemplo, el empleo de la oxitocina artificial empleada en un principio para la inducción de los partos en caso de necesidad, se estandariza en la mayoría de los casos provocando partos más dolorosos provocando que la analgesia epidural fuese cada vez más solicitada.

En este contexto, las cesáreas alcanzaron niveles elevados, desde un $2 \%$ hasta un $12 \%$ en el Reino Unido o un 25\% en USA; también aumentaron los partos instrumentados. Por otro lado, los avances científico-técnicos disminuyeron la mortalidad materno-infantil, dieron lugar a un mayor control del estado fetal por medio de la monitorización y se utilizaron cada vez más los registros en partogramas. A medida que el siglo avanzaba la medicina se implicó más en la salud de las mujeres provocando un sentimiento de pérdida de control en las funciones naturales del organismo debido a la invasión medicalizada del cuerpo; la práctica de la episiotomía se tornó cotidiana después de los años 50 y fue entonces cuando grupos de mujeres realizaron campañas en contra de la episiotomía innecesaria. A mitad de la década de los 70 se desarrolló una confrontación importante en Europa y USA entre la sociedad y los obstetras, dejando así paso a la escucha femenina; estos años pueden destacarse por el comienzo de un nuevo "cambio". 
Las reivindicaciones de mujeres es un acontecimiento social, que junto a otras corrientes de pensamiento hacen cambiar las acciones políticas y de las Ciencias Sociales. Las Instituciones Internacionales, gestadas y avaladas desde Occidente, pretenden la igualdad de derechos, acontecimientos como la Proclamación del Año Internacional de la Mujer en 1975, la cumbre en Ginebra en 1992 sobre el adelanto económico de la mujer rural, o la Cuarta Conferencia Mundial sobre la Mujer en 1995, abrieron una luz a la conciencia internacional.

En nuestro país, con la Constitución Española de 1978, la mujer adquiere derechos civiles y, veintitrés años después, la Declaración de Madrid en el año 2001 propone equidad de género en salud por medio del mainstreaming. El concepto de género es cultural y se aplica a la política y la técnica requiriendo cambios en la manera de pensar, así como en los objetivos, estructuras y distribución de recursos en los órganos internacionales, gobiernos y organizaciones no gubernamentales.

Siguiendo con España, en noviembre de 2004 se funda el Observatorio de Salud las Mujeres por el Ministerio de Sanidad y Consumo, otro nexo entre sociedad y Estado. Es fruto de las reuniones internacionales para lograr la equidad en salud entre géneros. En diciembre de 2005 tuvo lugar el II Foro de Mujeres, Salud y Género organizado por el Ministerio de Sanidad y Consumo, y su fruto lo estamos experimentando hoy desde que en 2007 se publica la Estrategia de Atención al Parto Normal (EPN), de la que se deriva la Iniciativa al Parto Normal (IPN) elaborada la Federación de Asociaciones de Matronas de España (FAME). El objetivo es impulsar algunos cambios en la atención al parto; se pretende llegar a un consenso entre las madres-padres (sociedad) y los profesionales para un acuerdo en la atención, de ahí la creación del Plan de Parto.

Son diversos los cambios que el SNS (Sistema Nacional de Salud) tiene que asumir, la sociedad cambia, hay muchas mujeres y organizaciones que piden modificaciones y se deben escuchar. La asunción de competencias por las Comunidades Autónomas favorece los cometidos del SNS manteniendo una identidad común. Esto en teoría debe facilitar la adaptación de la sanidad a los cambios sociales, pero como vemos es un proceso lento y no siempre se mueve en la dirección de todos. No obstante, se plantea tres requisitos indispensables para asegurar el derecho de los ciudadanos a la protección de la salud: la equidad, la calidad y la participación en la asistencia. Actualmente en nuestro país mediante los contratos de Gestión Sanitaria en las Comunidades Autónomas se persigue la Calidad en la Asistencia y, con ello, la instauración de la IPN, como hemos dicho elaborada por las matronas españolas tomando como referencia las opiniones de la comunidad, donde se valora la capacidad de decisión de las mujeres sobre su cuerpo. Las matronas han concebido a la mujer desde una perspectiva integral y de heterogeneidad, no sólo acompañando en el proceso reproductivo, sino además en todas las etapas de la vida. El acceso a la mujer y su entorno implica entender las condiciones particulares de cada una respetando sus decisiones.

En los últimos años son muchas las asociaciones que han surgido en España caracterizadas por la diversidad de actividades y objetivos, pese a las diferencias, estas agrupaciones tienen en común el cuestionamiento de las relaciones de género con tres directrices principales basadas en la reivindicación de identidades negadas, la solución de carencias y la identificación con las más desfavorecidas. El 
sistema biomédico ha chocado con su propia medicina, la atención holística al ser humano se relega a los avances tecnológicos y a un sin fin de pruebas diagnósticas o tratamientos. Las redes sociales de autoayuda cubren necesidades que el sistema no oferta ya que cumplen otras funciones de carácter personal y comunitario ajenas a intereses políticos, un ejemplo lo encontramos en la creación de asociaciones como EPEN (El Parto Es Nuestro); si analizamos algunos de los testimonios recogidos en su Web podemos ver reflejada la situación a la que se han visto sometidas algunas mujeres.

Actualmente nos encontramos en un momento de cambio (cambio social y cultural) la reivindicación a nivel mundial de las mujeres por la "naturalidad" del parto que ofrece una matrona, y el apoyo de organizaciones y encuentros internacionales, favorece que nuestra profesión se tome en cuenta durante la vida de las mujeres. Las matronas debemos apoyar nuestro propio proyecto de futuro, que acorde con la OMS desarrollará una definición de nuestro rol, claro y asumido desde la antigüedad y asaltado por la historia. La asociación capacita al grupo para la defensa y reivindicación de prioridades, facilitando la comunicación intra e interdisciplinar.

En España, la Federación de Asociaciones de Matronas de España (FAME) y la Asociación Nacional de Matronas, representan a todas las matronas españolas ante los organismos e instituciones nacionales e internacionales, velando por el desarrollo y aplicación de la legislación que concierne al ámbito de la formación y ejercicio profesional, al mismo tiempo promueve la calidad del cuidado de la salud integral de la mujer, en especial la sexual y reproductiva. 